Original Research Paper

\title{
Determination of the Mutagenicity of 2-aminoanthracene Using Chicken Hepatic S-9 Fraction
}

\author{
${ }^{1}$ Vladimir A. Chistyakov, ${ }^{1}$ Alexander V. Usatov, ${ }^{2}$ Aleksander I. Klimenko, \\ ${ }^{2}$ Maria A. Kolosova, ${ }^{1}$ Eugenia V. Prazdnova and ${ }^{3}$ Alexey V. Tutel'ian \\ ${ }^{1}$ Southern Federal University, Rostov-on-Don, 344006, Russia \\ ${ }^{2}$ Don State Agrarian University, Persianovski, 346493, Russia \\ ${ }^{3}$ Sechenov University, Moscow, 119991, Russia
}

Article history

Received: 02-09-2018

Revised: 23-10-2018

Accepted: 14-11-2018

Corresponding Author:

Maria A. Kolosova,

Don State Agrarian University,

Persianovski, 346493, Russia

Email:m.leonovaa@mail.ru

\begin{abstract}
The abundance of potential genotoxins makes it necessary to improve microbial test systems that allow to identify these substances quickly. At the same time, the methodology of metabolic activation of promutagens in vitro is very important. Microsomal preparations of rodents, which are generally used for that, have significant disadvantages associated with the potential health risks of the inducers of the metabolism of microsomal cytochromes. For the metabolic activation of promutagens, we have developed a protocol of microsomal homogenate fraction (S-9) preparation. We propose to complement the set of methods for quality control of feeds for valuable and rare chicken breeds with the Ames test (Salmonella/microsome) using the activated chicken hepatic S-9 homogenate fraction.
\end{abstract}

Keywords: Ames Test (Salmonella/microsome), S-9 Fraction, Genotoxicity, Mutagenicity, Chicken

\section{Introduction}

Quality control of feed, mixed fodders and mixed fodder raw materials is an important requirement for increasing productivity in poultry farming (Guerre, 2016). All feed and feed supplements are tested according to standard parameters characterizing its nutritional value, toxicological status and microbiological safety (Komarova, 2013; Turitsyna and Donkova, 2010; Tutel'ian, 2004). However, the feed quality control does not provide the exhaustive analysis of the presence of potential genotoxins, which can result, when using these feeds, in increasing the genetic load in both birds and humans. It is known that both chemical plant protection products and other anthropogenic pollutants can accumulate and cause the development of fodder toxicoses in poultry (Alexandrov, 2000) and, subsequently falling into food, genotoxic (Dubinin, 1977; Kurinny, 1983; Abilev, Glaser, 2015; Kier and Kirkland, 2013), carcinogenic effect and consequently, are a serious threat to human health (Abilev, Glaser, 2015; Poirier, 2016; Lin et al., 2016; Roos et al., 2016).

For screening of potential mutagens for humans, microbial test systems are widely used (Biran et al., 2010). The basis for such an approach was provided by Bruce Ames, author of the Salmonella/microsome test. The Ames test is based on the detection of reversion to the wild type of mutated histidine cells (His-) on a media lacking in histidine (Ames et al., 1975). One of the biggest drawbacks of all bacterial test systems is the lack of the xenobiotics metabolic biodegradation system inherent in vertebrates, so the metabolic activation of the test sample is a mandatory stage of screening using bacterial tests. To capture the contribution of biotransformation to the mutagenicity of xenobiotics, a microsomal fraction of the liver (a supernatant after centrifugation of the liver homogenate at $9000 \mathrm{~g}$, the socalled S-9 fraction) is used. Hepatic S-9 homogenate fraction contains microsomes and cytosol with the main metabolic enzymes of both I and II phases of the metabolism: cytochrome P450, flavin monooxygenase, aldehyde oxidase, glutathione transferase, monoamine oxidase, UDP (uridine 5-diphosphate glucoronosyl transferase) and others.

Typically, for metabolic activation of promutagens, a commercial preparation S-9, obtained from rat liver, is used. However, the metabolism of xenobiotics in birds and mammals is no identical (Hutchinson et al., 2014). In particular, in the 1980s it was demonstrated by the employees of faculty of Genetics at the Leningrad State University (now St. Petersburg State University) that the metabolic features of the chicken liver allow to obtain preparations with a high ability for metabolic activation of promutagenes without the induction of birds by 
phenobarbital or arochlore (Pavlov et al., 1985). Thus, a standard protocol for the metabolic activation of promutagen using the chicken hepatic S-9 fraction can be a useful addition to a set of genotoxicity control methods.

\section{Materials and Methods}

The research was carried out according to the approved conditions at JV «Svetly», which is a structural unit of CJSC «Agrofirma Vostok» (Volgograd region, Russia), the sow farm of the second order for poultry breeding «Highsex Brown». Parent herd of the «Highsex Brown» cross (hatched on August 25, 2016) was obtained from the Sverdlovsk PPR Ltd. (Sverdlovsk Region). Each experimental bird was contained in the cell battery Big Dutchman (Germany). The microclimate parameters were set according to the recommendations of the manufacturer of cross-country «Highsex Brown» company «ISA Hendrix Genetics» (Holland). The birds were fed with the standard mixed fodder manufactured at the feed mill of the company. Feeding of the experimental birds was carried out according to NRC (Subcommittee on Poultry Nutrition, National Research Council (1994) Nutrient Requirements of Poultry: Ninth Revised Edition, National Academy Press, Washington D.C.). In the experiment were taken birds of the age of 133 days, weighing 1.8-2.0 kg. The mutagenic activity was determined by the method of (Mortelmans, Zeiger, 2000).

\section{Statistical Processing of Experimental Data}

The statistical significance of the differences was determined by Student's t-test for independent samples at $\mathrm{p}<0.05$.

\section{Ethics of Biological Experiments}

Experiments on animals were conducted in accordance with the principles of the European Convention for the Protection of Vertebrate Animals, used for experiments or for other scientific purposes.

\section{Optimization of the Protocol for Obtaining the Hepatic S-9 Fraction}

Five preparations were used to optimize the protocol for the production of the hepatic S-9 fraction.

Preparation №1 was obtained on the basis of rat hepatic S-9 homogenate obtained according to a standard procedure using Arochlore 1254 (Sigma-Aldrich) (Vogel, 2006). The protein content in the preparation is $10 \mathrm{mg} / \mathrm{ml}$ (biuret method http://www.olvexd.ru/catalog/biohim-nabori/substraty/tovar-71.html). The final product was stored at a temperature of $-80^{\circ} \mathrm{C}$, indicated in the standard protocol (Ames et al., 1975).

The quality of the preparation was examined depending on the conditions of its storage. Storage of S9 fractions is important for the screening of genotoxicants. There is an opinion that enzymes of microsomal fractions show instability under storage conditions at $-20^{\circ} \mathrm{C}$ and above. For example, some denaturing agents, such as proteases, are active at $-20^{\circ} \mathrm{C}$ (Hubbard et al., 1985). Therefore, the preparation №2 was prepared in a manner similar to that used for preparation №1, except that the finished product was stored at $-20^{\circ} \mathrm{C}$.

Preparation №3 was prepared according to the following procedure. The birds were decapitated, the blood drained, the carcasses immediately opened, the liver was removed, washed with sterile $0.1 \mathrm{M} \mathrm{KCl}$ and placed on ice. The liver was then homogenized in a steel mechanical homogenizer (MPW-302, Poland) for $2 \mathrm{~min}$ at $2000 \mathrm{rpm}$ (pre-homogenization) followed by homogenization in a Potter homogenizer with teflon pestle in 9 volumes of $0.15 \mathrm{M} \mathrm{NaCl}$. All homogenization operations were also maid on ice. Isolation of the microsomal fraction was carried out by differential centrifugation according to a standard procedure (Abilev and Glaser, 2015). The protein content of the preparation was adjusted to $10 \mathrm{mg} / \mathrm{mL}$, diluted with a homogenization buffer. The final product was stored at $-20^{\circ} \mathrm{C}$.

Preparation №4 was prepared in a manner similar to that used for preparation №3, except that the final product was stored at $-80^{\circ} \mathrm{C}$.

Preparation №5 was prepared in a manner similar to that for preparation №3, except that $3 \%$ of glycerol was added to the homogenization buffer and the final product was stored at $-20^{\circ} \mathrm{C}$ with glycerol added to a concentration of $30 \%$.

As a standard promutagen requiring metabolic activation, a solution of 2-aminoanthracene (Serva) in DMSO (Sigma-Aldrich) was used at concentrations of 5, 10 and $50 \mu \mathrm{g} / \mathrm{mL}$. As a negative control, DMSO was added to the plate.

Before use, the preparations were stored for 30 days under the above conditions.

\section{Results}

The results of testing the quality of microsomal fractions are shown in Table 1. The activity of preparations №1 and №2, based on the microsomal fraction of the rat, is sufficient to detect the mutagenicity of all treatment options, except for the effect of a minimum dose of 2-aminoanthracene on strain TA98. The study of the quality of the preparation of rat hepatic S-9 fractions showed no significant differences in the activity of the preparations stored at $-80^{\circ} \mathrm{C}$ и $-20^{\circ} \mathrm{C}$. The minimal activating ability was shown by the preparation №3 from the chicken liver, prepared without a cryoprotectant. The Ames test using TA100 and TA98 strains and this preparation does not allow detection of the mutagenic effect of 2-aminoanthracene in a dose of 1 $\mu \mathrm{g}$ per plate. Preparations №4 and №5 are effective for all combinations of doses and strains. The use of these preparations allows for greater sensitivity compared to the standard protocol based on the preparation №1. 
Table 1: Comparison of the effectiveness of metabolic activation using rat hepatic S-9 homogenate and bird hepatic S-9 homogenate

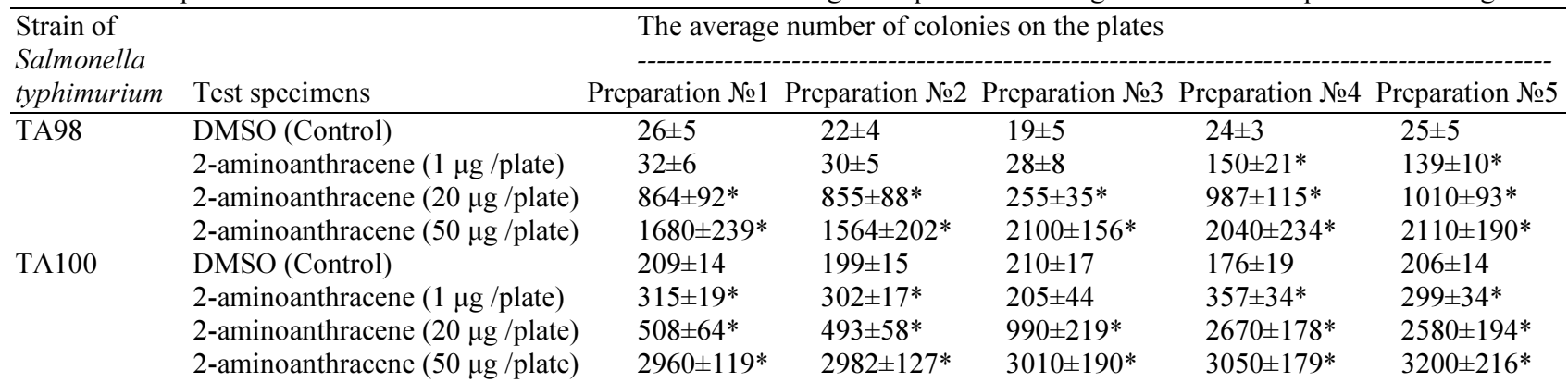

*- a statistically significant mutagenic effect (t-test, $\mathrm{p}<0.05)$

\section{Discussion}

It should be noted that the priority for the use of the liver of chickens for the activation of promutagenes belongs to Russian scientists (Pavlov et al., 1985). An investigation of the frequency of induced mutations in a system of indicator microorganisms/cell extracts of animals and birds liver (Salmonella/microsome test) was conducted to analyze the mechanisms of mutagenesis. In the study of the metabolic activation of 2-aminofluoren, the higher activity of chicken liver microsomes was first demonstrated in comparison with liver preparations of mice (Pavlov et al., 1985), even after preliminary induction of the latter with a mixture of polychlorinated biphenyls, which increases the activity of cytochromes P-450 family enzymes by tenfold (Benford et al., 1988).

\section{Conclusion}

Thus, it can be concluded that although the chicken hepatic S-9 homogenate preparation was prepared and stored according to the standard procedure allows one to detect the genetic activity of the promutagen used in principle, it has an increased demand for the storage temperature (Table 1). However, the introduction of the cryoprotectant (glycerol) into the homogenization buffer and the storage buffer has made it possible to compensate for this deficiency.

Our research showed that minor changes in the test protocol make it possible to obtain chicken hepatic S-9 homogenate preparations, which are less demanding for storage conditions, that makes the process of its estimation more cost-effective and also provide a higher sensitivity to the mutagenic effect of 2aminoanthracene in the Ames test.

\section{Funding Information}

This research was supported by Russian Science Foundation project no.16-16-04032.

\section{Acknowledgement}

We thank I.F. Gorlov, Doctor of Agricultural Sciences, Academician of the Russian Academy of Sciences, for valuable and constructive suggestions during the planning and development of this research work.

\section{Author's Contributions}

Alexey V. Tutel'ian and Aleksander V. Usatov: Designed and performed experiments and wrote the paper.

Eugenia V. Prazdnova and Vladimir A. Chistyakov: Developed analytical tools and analyzed data.

Aleksander I. Klimenko and Maria A. Kolosova: Collected and analyzed data.

\section{Ethics}

This article is original and contains unpublished materials. The corresponding author confirms that all of the other authors have read and approved the manuscript and no ethical issues involved.

\section{References}

Abilev, S.K. and V.M. Glaser, 2015. Mutagenesis with the basics of genotoxicology. Nestor-Istorija, Moscow, St. Petersburg. ISBN: 978-5-4469-0591-1, pp: 304.

Alexandrov, Y.A., 2000. Feed Toxicosis of Farm Animals and Birds. Mar. State. Un-t., Yoshkar-Ola. ISBN: 5-230-00587-4, pp: 88.

Ames, B.N., McCann, J. and E. Yamasaki, 1975. Methods for detecting carcinogens and mutagens with the Salmonella/mammalian-microsome mutagenicity test. Mutation Res., 31: 347-364. DOI: 10.1016/0165-1161(75)90046-1

Benford, D.J., H.J. Reavy and S.A. Hubbard, 1988. Metabolizing systems in cell culture cytotoxicity tests. Xenobiotica, 18: 649-656. DOI: $10.3109 / 00498258809041703$ 
Biran, A., S. Yagur-Kroll, R. Pedahzur, S. Buchinger and G. Reifferscheid et al., 2010. Bacterial genotoxicity bioreporters. Microbial Biotechnol., 3: 412-427. DOI: 10.1111/j.1751-7915.2009.00160.x

Dubinin, N.P., 1977. Mutagenes of the Environment and Human Heredity. In: Genetic Consequences of Environmental Pollution, General Questions and Methodology Research, Dubinin N.P. (Ed.), Nauka, Moscow, pp: 3-20.

Guerre, P., 2016. Worldwide mycotoxins exposure in pig and poultry feed formulations. Toxins (Basel), 8: E350. DOI: 10.3390/toxins8120350

Hubbard, S.A., T.M. Brooks, L.P. Gonzalez and J.W. Bridges, 1985. Preparation and Characterisation of S-9 Fractions. In: Comparative Genetic Toxicology, Parry, J.M. and C.F. Arlett, (Eds.), Palgrave Macmillan, London. ISBN-10: 978-1-349-07903-2, pp: 413-438.

Hutchinson, T.H., J.C. Madden, V. Naidoo and C.H. Walker, 2014. Comparative metabolism as a key driver of wildlife species sensitivity to human and veterinary pharmaceuticals. Philosophical Transactions Royal Society B: Biological Sci., 369: 20130583. DOI:10.1098/rstb.2013.0583

Kier, L.D. and D.J. Kirkland, 2013. Review of genotoxicity studies of glyphosate and glyphosate-based formulations. Critical Rev. Toxicol., 43: 283-315. DOI:10.3109/10408444.2013.770820

Komarova, Z.B., 2013. Scientific and practical justification for the use of new feed additives in the production of competitive meat and egg products. Thesis for the degree of Doctor of Agricultural Sciences. Volgograd, pp: 330.

Kurinny, A.I., 1983. To the problem of prevention of genetic consequences of pesticide application: Reality and necessity. Tsitologiia i Genetika, 17: 16-21.

Lin, J.A., C.H. Wu, C.C. Lu, S.M. Hsia and G.C. Yen, 2016. Glycative stress from advanced glycation end products (AGEs) and dicarbonyls: An emerging biological factor in cancer onset and progression. Molecular Nutrition Food Res., 60: 1850-64. DOI: $10.1002 / \mathrm{mnfr} .201500759$
Mortelmans, K. and E. Zeiger, 2000. The Ames Salmonella/microsome mutagenicity assay. Mutation Res., 455: 29-60. DOI: $10.1016 / \mathrm{S} 0027-5107(00) 00064-6$

Pavlov, Y.I., N.N. Khromov-Borisov, L.P. Shevchenko, L.A. Alekseyevitch and S.G. Inge-Vechtomov, 1984. Comparisons of the promutagen-activating capacity of S-9 liver preparations from mouse and chicken using in vitro tests with Salmonella and yeast. Mutation Res., 140: 75-9.

DOI: $10.1016 / 0165-7992(84) 90046-0$

Poirier, M.C., 2016. Linking DNA adduct formation and human cancer risk in chemical carcinogenesis. Environ. Molecular Mutagenesis, 57: 499-507. DOI: $10.1002 / \mathrm{em} .22030$

Roos, W.P., A.D. Thomas and B. Kaina, 2016. DNA damage and the balance between survival and death in cancer biology. Nature Rev. Cancer, 16: 20-33. DOI: $10.1038 /$ nrc. 2015.2

Subcommittee on Poultry Nutrition, National Research Council, 1994. Nutrient Requirements of Poultry. 9th Edn., National Academy Press, Washington D.C., ISBN: 978-0-309-04892-7, pp: 176.

Turitsyna, E.G. and N.V. Donkova, 2010. Problems of complex application of means of specific and nonspecific prophylaxis in industrial poultry farming. Vestnik KrasAA, 7: $101-107$.

Tutel'ian, A.V., 2004. Development of an evaluation system for immunotropic drugs of natural and synthetic origin on the basis of an analysis of the relationship between immune and antioxidant protection. Thesis of $\mathrm{PhD}$ Medical Sciences, Moscow, pp: 220.

Vogel, H.G., 2006. Drug Discovery and Evaluation: Safety and Pharmacokinetic Assays. SpringerVerlag, Berlin Heidelberg New York. ISBN: 3-540-25638-5, pp: 894. 